\title{
Culture of Mouse Amniotic Fluid-Derived Cells on Irradiated STO Feeders Results in the Generation of Primitive Endoderm Cell Lines Capable of Self-Renewal in vitro
}

\author{
Aleksandar M. Babic ${ }^{a, b}$ Sunyoung Jang ${ }^{d}$ Eugenia Nicolov ${ }^{a}$ Horatiu Voicu $^{c}$ \\ Chance J. Luckey ${ }^{\mathrm{d}}$ \\ a Department of Pathology and Genomic Medicine, The Methodist Hospital, ${ }^{\mathrm{b}}$ Center for Cell and Gene Therapy, and \\ 'The Genomic and RNA Profiling Core, Baylor College of Medicine, Houston, Tex., and d Department of Pathology, \\ Brigham and Women's Hospital, Boston, Mass., USA
}

\section{Key Words}

Amniotic fluid · Fetal anomalies · Primitive endoderm .

Self-renewal

\begin{abstract}
The cells present in amniotic fluid (AF) are currently used for prenatal diagnosis of fetal anomalies but are also a potential source of cells for cell therapy. To better characterize putative progenitor cell populations present in AF, we used culture conditions that support self-renewal to determine if these promoted the generation of stable cell lines from AFderived cells (AFC). Cells isolated from E11.5 mouse were cultured on irradiated STO fibroblast feeder layers in human embryonic germ cell derivation conditions. The cultures grew multicellular epithelial colonies that could be repropagated from single cells. Reverse transcription semiquantitative polymerase chain reaction of established cell lines revealed that they belonged to the extraembryonic endoderm (ExEn) expressing high levels of Gata6, Gata4, Sox17, Foxa2 and Sox7 mRNA. Hierarchical clustering based on the whole transcriptome expression profile of the AFC lines (AFCL) shows significant correlation between transcription profiles of AFCL and blastocyst-derived XEN, an ExEn cell line. In vitro differentiation of AFCL results in the generation of cells ex-
\end{abstract}

pressing albumin and a-fetoprotein (AFP), while intramuscular injection of AFCL into immunodeficient mice produced AFP-positive tumors with primitive endodermal appearance. Hence, E11.5 mouse AF contains cells that efficiently produce XEN lines. These AF-derived XEN lines do not spontaneously differentiate into embryonic-type cells but are phenotypically stable and have the capacity for extensive expansion. The lack of requirement for reprogramming factors to turn AFderived progenitor cells into stable cell lines capable of massive expansion together with the known ability of ExEn to contribute to embryonic tissue suggests that this cell type may be a candidate for banking for cell therapies.

(c) 2013 S. Karger AG, Basel

\section{Introduction}

In amniotes, the fetus develops inside an amniotic sac that is filled with amniotic fluid (AF), and both contribute to a stable environment and allow movement of the developing fetus. The fluid also contains several cell types of fetal and perhaps amniotic membrane origin. These cells were previously classified by differences in morphology [Gosden, 1983], surface phenotype, and differentiation potential [De Coppi et al., 2007; Klein and Fauza, 2011]

\section{KARGER}

E-Mail karger@karger.com

www.karger.com/cto
(C) 2013 S. Karger AG, Basel

1422-6405/13/1982-0111\$38.00/0
Dr. Aleksandar M. Babic

Center for Cell and Gene Therapy, Feigin Center

1102 Bates Avenue

Houston, TX 77030 (USA)

E-Mail clone_007@yahoo.com 


\begin{tabular}{ll}
\hline Abbreviations used in this paper \\
\hline AF & amniotic fluid \\
AFC & amniotic fluid-derived cells \\
AFCL & amniotic fluid-derived cell lines \\
AFP & a-fetoprotein \\
AFSC & amniotic fluid stem cells \\
ALB & albumin \\
BMP4 & bone morphogenic protein 4 \\
CXCR4 & C-X-C chemokine receptor type 4 \\
DE & definitive endoderm \\
EGC & embryonic germ cells \\
ESC & embryonic stem cells \\
ExEn & extraembryonic endoderm \\
FBS & fetal bovine serum \\
FGF-2 & fibroblast growth factor-2 \\
FACS & fluorescence-activated cell sorting \\
iPSC & induced pluripotent stem cells \\
LIF & leukemia inhibitory factor \\
MEF & mouse embryonic fibroblasts \\
MSC & mesenchymal stem cells \\
PCR & polymerase chain reaction \\
PE & parietal endoderm \\
PrE & primitive endoderm \\
PDGFRA & platelet-derived growth factor receptor-a \\
qPCR & semiquantitative PCR \\
RT & reverse transcription \\
SCF & stem cell factor \\
VE & visceral endoderm \\
XEN & extraembryonic endoderm cell line \\
\hline &
\end{tabular}

and are also considered to be of potential clinical significance for cell therapy of several types of congenital tissue defects [Kunisaki et al., 2007; Steigman et al., 2009; Gray et al., 2012]

To characterize the progenitor potential of cell populations from AF, it is necessary to achieve ex vivo expansion of relatively homogenous cell populations. Previously, this was accomplished using several methodologies, including protocols for culture of mesenchymal stem cells (MSC) [Kaviani et al., 2003; Klein and Fauza, 2011], expansion protocols used for clinical cytogenetics [De Coppi et al., 2007], or a combination of an MSC derivation protocol followed by culture in serum-free media for human embryonic stem cells (ESC) and induced pluripotent stem cells (iPSC) [Moschidou et al., 2013]. These approaches establish multipotent populations of cells with limited self-renewal ability, further described as either MSC [Klein and Fauza, 2011] or c-KIT+ AF-derived stem cells (AFSC) with ability to initiate adipogenic, osteogenic, myogenic, endothelial, neuronal, and hepatic differentiation in vitro [De Coppi et al., 2007; Moschidou et al., 2012]. Using an alternative approach, we sought to estab- lish stable c-KIT+ cell lines with self-renewal capacity by explanting mouse AF-derived cells (AFC) in embryonic germ cell (EGC) derivation conditions, previously used to establish stable cell lines from c-KIT+ primordial germ cells [Shamblott et al., 1998].

Explantation has been used to generate different types of self-renewing cell lines [Jaenisch and Young, 2008], including ESC from different species [Evans and Kaufman, 1981; Martin, 1981; Thomson et al., 1995, 1996, 1998], mouse epiblast stem cells [Brons et al., 2007; Tesar et al., 2007], and mouse [Matsui et al., 1992; Resnick et al., 1992] and human EGC [Shamblott et al., 1998], and it is also an important step in the culture of iPSC [Takahashi et al., 2007]. During explantation, primary progenitor cells are cultured in conditions that support and stimulate self-renewal, typically through the addition of growth factors such as mouse recombinant leukemia inhibitory factor (LIF) and/or human recombinant basic fibroblast growth factor (FGF-2), mitotically inactivated mouse embryonic fibroblasts (MEF), and specially screened lots of fetal bovine serum (FBS) or commercial serum replacer until stable cell lines are successfully generated. In addition to its usefulness in the generation of pluripotent stem cell lines, explantation can also be used to derive lineage-committed permanent cell lines such as extraembryonic endoderm (ExEn) cell lines (XEN) [Kunath et al., 2005; Brown et al., 2010] and trophoblast cell lines [Tanaka et al., 1998].

In this report, we describe the successful derivation of self-renewing cell lines from E11.5 mouse AF using EGCtype explantation [Shamblott et al., 1998]. In addition, we show that these cell lines have the phenotypic and gene expression profiles most similar to blastocyst-derived XEN cells, and we demonstrate their in vitro and in vivo primitive endoderm $(\mathrm{PrE})$ lineage differentiation potential.

\section{Materials and Methods}

AF Cell Line Generation and Culture

Cell lines were derived from mouse strain 129X1/SvJ (Jackson Laboratory). Mouse AF was obtained from dissected intact E11.5 amniotic sacs through micropuncture. The collected cells were filtered using a $40-\mu \mathrm{m}$ cell strainer (BD Biosciences) followed by a single washing step in high-glucose DMEM (Hyclone) with $10 \%$ FBS (Sigma). Cells isolated from 5 amniotic sacs were plated into a single well of a tissue culture-treated 12-well plate containing irradiated STO feeders (56-X; ATCC) at a density of 110,000 cells/ $\mathrm{cm}^{2}$. The plating media consisted of knockout DMEM/F12 (Gibco) with $15 \%$ of ESC-screened FBS (Sigma), $0.1 \mathrm{mM}$ nonessential amino acids, $2 \mathrm{mM}$ glutamine, $1 \mathrm{~mm}$ sodium pyruvate (Gibco), $1 \times$ 
EmbryoMax nucleosides (Millipore), $0.14 \mathrm{~mm}$ 2-mercaptoethanol (Sigma), 1,000 U/ml ESGRO (Millipore), 2 ng/ml FGF-2 (Invitrogen), $10 \mu \mathrm{M}$ forskolin (Sigma), and $25 \mathrm{ng} / \mathrm{ml}$ mouse recombinant stem cell factor (SCF; R\&D Systems). During the first 4 passages, culture splitting was performed every $8-9$ days using $0.25 \%$ trypsin EDTA solution followed by vigorous pipetting to obtain a singlecell suspension. Upon the appearance of the first colonies $(\sim 4$ weeks), the culture of AFC lines (AFCL) was continued using mitomycin C-treated MEF feeder cells, strain CF-1 (Millipore), in the absence of forskolin or SCF. During routine culture, established cell lines were grown to subconfluence and passaged every 3-4 days using $0.05 \%$ trypsin EDTA or TrypLE Express solution (Invitrogen). We cryopreserved cells in freezing media containing 10\% DMSO (Acros Organics). Mouse ESC (CCE line) were cultured using standard methods (ATCC). The XEN10 cell line, a kind gift from Drs. A.C. Foley and A.K. Hadjantonakis, was cultured as described by Brown et al. [2010].

\section{Doubling-Time Analysis}

For this analysis, cells of each AFCL were initially plated at $15,625 \mathrm{cells} / \mathrm{cm}^{2}$ in a gelatinized 6 -well plate preseeded with 20,000 cells $/ \mathrm{cm}^{2}$ of irradiated CF-1 fibroblasts in a regular AFCL growth medium. Upon reaching $80-90 \%$ confluence, each AFCL was replated in triplicate at 15,625 cells $/ \mathrm{cm}^{2}$ in gelatinized wells of a 6-well plate preseeded with the above-described number of irradiated CF-1 fibroblasts. After $46 \mathrm{~h}$, cells were treated with TrypLE Express solution and live cells were counted. The counts were normalized for the numbers of remaining irradiated CF-1 fibroblasts. The doubling time (DT) was calculated as previously described [Moschidou et al., 2012]: DT $=\mathrm{t} /\left[\log _{2}(\mathrm{y} / \mathrm{m})\right]$, where $\mathrm{t}=$ time in culture, $y=$ number of cells at the end of the culture, and $m=$ number of cells at the beginning of the culture.

\section{Semiquantitative Polymerase Chain Reaction}

Total RNA extraction was performed using an RNeasy Plus Mini kit (Qiagen) followed by reverse transcription with a QuantiTect reverse transcription kit (Qiagen) using $500 \mathrm{ng}$ of total RNA in each reaction. Real-time polymerase chain reaction (PCR) was performed on $1 / 20$ of the reverse transcription reaction volume as a template using the Power SYBR Green PCR Master Mix (Applied Biosystems). The primers for the Gata6, Gata4, Pou5f1, Sox2, Nanog, Sox7, Sox17, Sall4, Lin28a, and Alb were synthesized by Sigma-Aldrich based on sequences suggested by the Primer Express 3.0 software (Applied Biosystems). Primers for mouse 18s RNA, Afp, Foxa 2 and Utf1 were manufactured by Qiagen. Samples were analyzed using the Applied Biosystems StepOne real-time PCR instrument. We analyzed results using one-way ANOVA followed by Tukey's multiple comparison test functions by GraphPad Prism software. For the list of primer sequences and cycling conditions, see online supplementary table S1 (for all online supplementary material, see www. karger.com/doi/10.1159/000353942).

\section{Immunostaining of Cultured Cells}

We stained cells cultured in a 4-well CultureSlide (BD Falcon) coated with $0.1 \%$ gelatin solution (Millipore) for $1 \mathrm{~h}$ at room temperature, using SALL4, UTF1, LIN28, GATA6, and FOXA2 antibodies at the following dilutions: SALL4 1:200 (ab29112; Abcam), UTF1 1:300 (ab24273; Abcam), LIN28 1:300 (ab63740; Abcam), GATA6 1:200 (ab22600; Abcam), and FOXA2 1:300 (sc-6554; San- ta Cruz Biotech). Cells cultured on collagen I-coated 4-well CultureSlide were stained for $\alpha$-fetoprotein (AFP) and albumin (ALB) as described previously [Gouon-Evans et al., 2006]. For all other antibodies, cells were fixed with $4 \%$ methanol-free formaldehyde for $10 \mathrm{~min}$ at room temperature and then washed three times with phosphate-buffered saline (PBS) followed by permeabilization with $0.2 \%$ Triton X-100 in PBS for $5 \mathrm{~min}$ (ALB and AFP) or $10 \mathrm{~min}$ (SALL4, UTF1, GATA6, and FOXA2). No additional permeabilization was performed for LIN28 staining. After 3 washes in PBS, the cells were blocked for $2 \mathrm{~h}$ at room temperature in PBS containing 5\% milk, 10\% normal goat serum (Jackson ImmunoResearch) and $0.1 \%$ Tween 20 (Sigma-Aldrich). Subsequently, cells were stained overnight at $4{ }^{\circ} \mathrm{C}$ with primary antibody or rabbit IgG (Santa Cruz Biotech) diluted in blocking buffer. The next day, cells were washed 3 times with PBS and stained for $1 \mathrm{~h}$ at room temperature with Alexa488-conjugated secondary antibody (1:200, Invitrogen). At the end of the staining period, cells were washed in PBS 3 times and counterstained with DAPI (Invitrogen) for $30 \mathrm{~min}$. Staining was visualized using either a Zeiss LSM 510 confocal system (UTF1, LIN28, and FOXA2), DeltaVision deconvolution microscope (SALL4, ALB, and AFP), or Nikon A1 confocal microscope (GATA6). We used ImageJ software (National Institutes of Health) for all image processing.

Tumor Formation Assay and Tissue Immunohistochemistry

The in vivo lineage potency of generated cell lines was assessed by intramuscular injection of $1 \times 10^{6} \mathrm{AFCL}$ or $0.5 \times 10^{6} \mathrm{ESC}$ (CCE, positive control) into the upper hind limb of NOD-SCID IL2R $\gamma^{\text {null }}$ immunodeficient mice (Jackson Laboratory), and teratoma/tumor formation was monitored for 3 months. Collected tumors were fixed in 25\% formalin and processed by the Pathology Core of the Dana-Farber/Harvard Cancer Center. Paraffin-embedded tissue was processed for AFP staining as described (R\&D Systems) except that the antigen retrieval step was performed for $45 \mathrm{~min}$ at $95^{\circ} \mathrm{C}$ using $\mathrm{pH} 9$ antigen retrieval solution (DAKO). Primary antibody against AFP (Ab-2, Neomarkers) was used at 1:100 dilution. Chromogenic detection of bound antibody was performed using an anti-rabbit HRP-DAB cell and tissue staining kit (R\&D Systems).

\section{In vitro Differentiation}

AFCL were grown to near confluence in DMEM/F12 (Invitrogen) media containing 15\% FBS and 5 ng/ml FGF-2 (R\&D Systems). Culture was performed on $0.1 \%$ gelatin-coated tissue culture plates containing mitotically inactivated CF-1 feeders at $35,000 / \mathrm{cm}^{2}$. The differentiation assay was initiated on day 0 by plating $\sim 1,000$ cells $/ \mathrm{cm}^{2}$ on collagen I-coated 6 -well plates or 4well CultureSlide in stage I serum-free media containing DMEM/ F12, $1 \times \mathrm{N} 2$ and B27 supplements (Invitrogen), $20 \mathrm{ng} / \mathrm{ml}$ human activin A, $20 \mathrm{ng} / \mathrm{ml}$ mouse recombinant bone morphogenic protein 4 (BMP4), $10 \mathrm{ng} / \mathrm{ml} \mathrm{FGF-2} \mathrm{(all} \mathrm{from} \mathrm{R \& D} \mathrm{Systems),} 0.45 \mu \mathrm{M}$ monothioglycerol (Sigma), and $50 \mu \mathrm{M}$ ascorbic-acid-2-phosphate (Sigma). On day 2, stage II of differentiation was initiated by changing the media to serum-free basic media, as described above, except that the growth factor combination used was mouse BMP4 (20 ng/ml), mouse recombinant epidermal growth factor (20 ng/ $\mathrm{ml}$; R\&D Systems), and FGF-2 (10 ng/ml). After 14 days, cells were either submitted to immunofluorescent analysis of AFP and ALB expression or to RNA extraction followed by semiquantitative PCR (qPCR) analysis, as described above. 


\section{Microarray Analysis}

For microarray analysis, each AFCL was cultured to subconfluence. Subsequently, cells were trypsinized with TrypLE Express solution and submitted to high-speed sorting using a DAKO-Cytomation MoFlo high-speed sorter; the c-KIT+ platelet-derived growth factor receptor- $\alpha$ (PDGFRA+) DAPI- cell population was sorted from each cell line in triplicate. Mouse ESC, CCE line, were submitted to the MEF removal step by allowing suspensions of trypsinized cells to attach to a gelatinized tissue culture dish for 45 min. Subsequently, nonattached cells were gently removed and submitted to RNA extraction. Total RNA from each sample was isolated using an RNeasy Plus Mini kit and subsequently analyzed by the Microarray Core at the University of Texas Health Science Center at Houston. Briefly, $300 \mathrm{ng}$ of total RNA were amplified and purified using an Illumina TotalPrep RNA amplification kit (Ambion). An aliquot of $1.5 \mu \mathrm{g}$ of amplified products was loaded onto Illumina Sentrix Beadchip Array mouse WG6.V2 arrays, hybridized at $58^{\circ} \mathrm{C}$ in an Illumina hybridization oven for $17 \mathrm{~h}$, washed, and incubated with streptavidin-Cy3 to detect biotin-labeled cRNA on the arrays. Arrays were dried and scanned with BeadArray Reader (Illumina). Microarray data were further analyzed as follows. The data were processed using the Lowess normalization algorithm. After normalization, additional processing was performed using a batch effect removal algorithm [Johnson et al., 2007] based on empirical Bayes methods. All arrays were adjusted so that they have similar distribution. To improve the outcome of the batch effect removal algorithm, all samples processed together with Xen10, Pys2, End2 and ESC samples were used as input. The intensities of all 45,281 probes were included in the calculation of $\mathrm{R}^{2}$. Hierarchical clustering was performed using the 'complete' algorithm and $1-\mathrm{R}^{2}$ as a metric. Heatmap tables were generated using the detection $\mathrm{p}$ value of 0.01 as a threshold. In case of multiple probes for the same gene, the probe with the highest intensity was reported. The Venn diagram analysis was based on genes whose probes were detected in all biological replicates. A detection $\mathrm{p}$ value of 0.01 was used.

Flow-Cytometric Analysis of Surface Marker Expression and Cell Cycle

Monolayer cultures of AFCL were dissociated using TrypLE Express ( $5 \mathrm{~min}$ ). Subsequently, isolated cells were stained with directly conjugated antibodies to c-KIT (catalog No. 561074, BD Biosciences) and PDGFRA (catalog No. 562776, BD Biosciences), or c-KIT and C-X-C chemokine receptor type 4 (CXCR4; catalog No. 558644, BD Biosciences) in staining buffer (HBSS + 2\% FBS) for $30 \mathrm{~min}$ followed by a single washing step. DAPI nuclear staining was used to exclude dead cells. Negative gates were established using isotype controls (catalog Nos. 551139 and 555844, BD Biosciences). Cell cycle analysis was performed as previously described [Mullen, 2004]. Stained cells were analyzed using BD FACSCalibur, LSRII and FlowJo software (Tree Star).

\section{Single-Cell Colony Formation Assay}

AFCL and ESC (CCE) were both cultured in the DMEM/F12based media containing 15\% ESC-screened FBS with $1,000 \mathrm{U} / \mathrm{ml}$ ESGRO, until 60-70\% confluence. To avoid sorting of feeder cells, AFCL were stained for flow cytometry using fluorophore-conjugated antibodies against c-KIT and PDGFRA (1:100) and CCE were stained with primary fluorescently labeled antibodies for SSEA-1 (catalog No. 560142, BD Biosciences) and EPCAM (cata- log No. 17-5791, eBioscience; 1:100), utilizing the above-described flow-cytometric protocol. Double-positive live cells were sorted as single cell/well into 96-well gelatinized flat-bottom tissue culturetreated plates (BD Falcon) containing previously seeded irradiated CF-1 fibroblasts (R\&D Systems) using a DAKO-Cytomation MoFlo high-speed sorter. Three plates were used for each cell line tested. For the secondary sorting experiment, 3 individual wells from 96-well plates, containing colonies, were expanded separately as subcloned cell lines in the original culture conditions for 7 days. Subsequently, the cells from each subclone were single-cell sorted into three 96-well plates each. All secondary plates were examined for colony formation after 7 days of culture. Statistical analysis and data plotting was performed using one-way ANOVA followed by Tukey's multiple comparison test in GraphPad Prism software.

\section{Electron Microscopy}

Sample preparation and imaging was performed by the MD Anderson Cancer Center Electron Microscopy Core Facility as follows: samples were treated with a fixative containing $2 \%$ glutaraldehyde in $0.1 \mathrm{M}$ PBS, pH 7.3, at $4^{\circ} \mathrm{C}$ overnight and then washed with $0.1 \mathrm{M}$ PBS buffer, $\mathrm{pH} 7.3,3 \times 10 \mathrm{~min}$. The samples were postfixed with $1 \%$ PBS-buffered osmium tetroxide for $1 \mathrm{~h}$, washed with $0.1 \mathrm{M}$ PBS, $3 \times 10 \mathrm{~min}$, followed by rinsing with distilled water, $2 \times$ $10 \mathrm{~min}$. Dehydration was performed with increasing concentrations of ethanol for $5 \mathrm{~min}$ each followed by treatment with hexamethyldisilazane and air drying overnight. Samples were mounted onto double-stick carbon tabs (Ted Pella) followed by coating under vacuum. Subsequently, platinum coating was performed under vacuum (thickness: $25 \mathrm{~nm}$ ) followed by carbon coating. Imaging was performed using a JSM-5910 scanning electron microscope (JEOL) at an accelerating voltage of $5 \mathrm{kV}$.

\section{Results}

\section{Irradiated STO Cells Are Required for the Generation of $c-K I T+A F C L$}

To initiate the EGC-type explantation protocol, we plated AFC on irradiated STO feeder cells in serum containing media in the presence of LIF, FGF-2, SCF, and forskolin. After 3-4 weeks in culture, we noted the first appearance of epithelial colonies (fig. 1a). Using these conditions, we reproducibly generated 3 stem cell lines from 129X1/SvJ mice. These cell lines were termed K82, $\mathrm{K} 83$, and K84, in chronological order. Importantly, when AFC were cultured on mitotically inactivated CF-1 fibroblast feeder cells plated at densities varying from 25,000 to 45,000 per $\mathrm{cm}^{2}$, using the above-described seeding and splitting protocol and media combination (including LIF, FGF-2, SCF, and forskolin), no observable colony formation occurred after 6 weeks of culture.

To assess the phenotypic stability of the above cell lines, we maintained each in culture for 20 passages over 10 weeks. All 3 cell lines had stable morphology, viabil- 

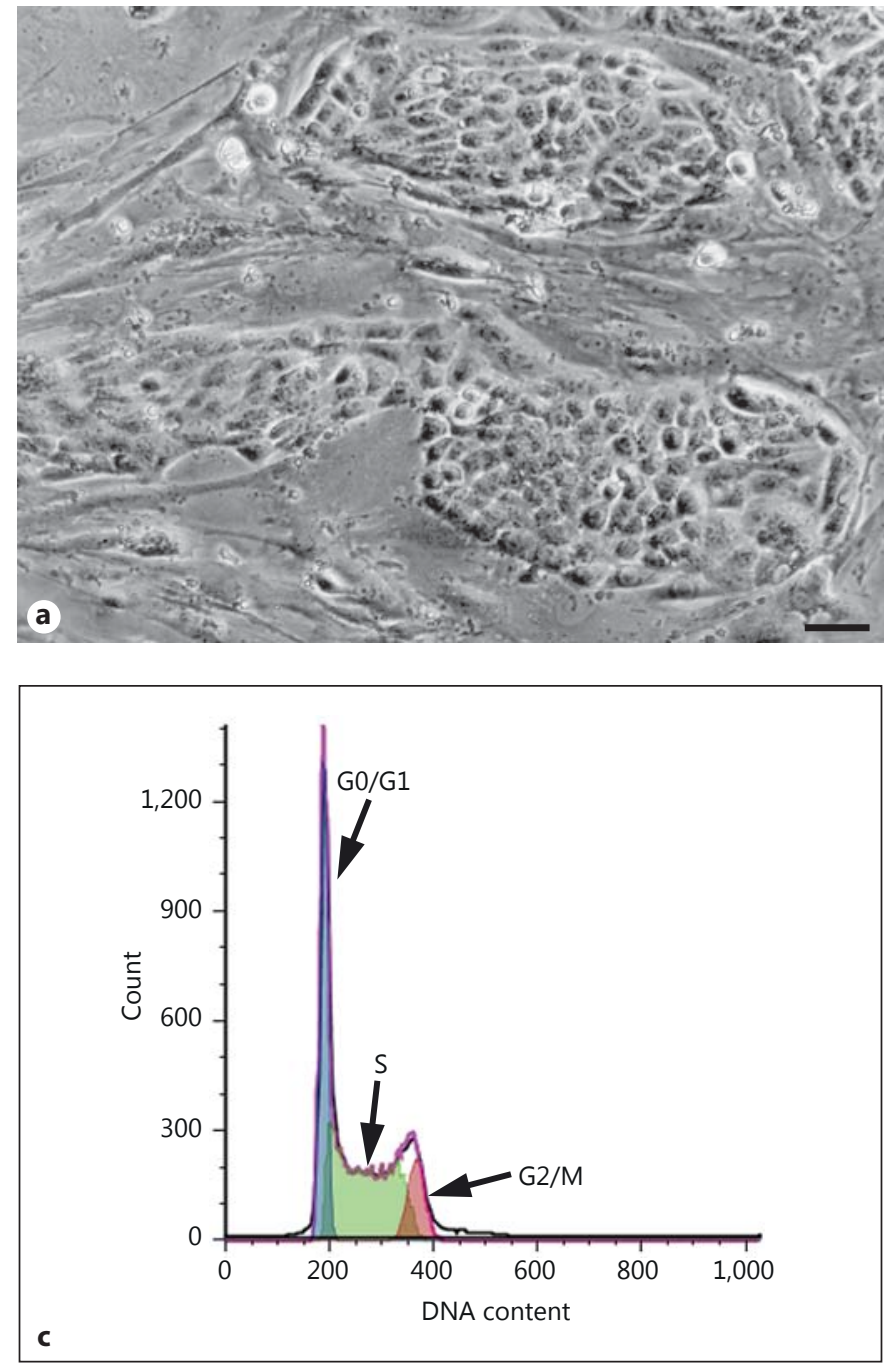

Fig. 1. Morphology, cell cycle analysis, and single-cell cloning of AFC. a Image of colonies of AFC nested among mitotically inactivated CF-1 fibroblast feeders (K82). Bar $=50 \mu \mathrm{m}$. b Results of primary (open bars) and secondary single-cell sorting (black bars) are

ity (data not shown), and growth characteristics (online suppl. fig. S1 and surface phenotype fig. S2 and S3).

A hallmark of self-renewal is the potential of cells to regenerate colonies from a single cell, so we used a highspeed cell sorter to deposit individual double-positive (CD117 and CD140a for AFCL or SSEA-1 and CD326 for ESC) live cells in each well of a 96-well plate previously seeded with fibroblast feeder cells. The results suggest that all AFCL have the capacity for clonal growth (fig. 1b). Importantly, the efficiency of single-cell sorting, calculated as the percent positive wells, from each AFCL is at least similar or higher (K82) compared to ESC. The
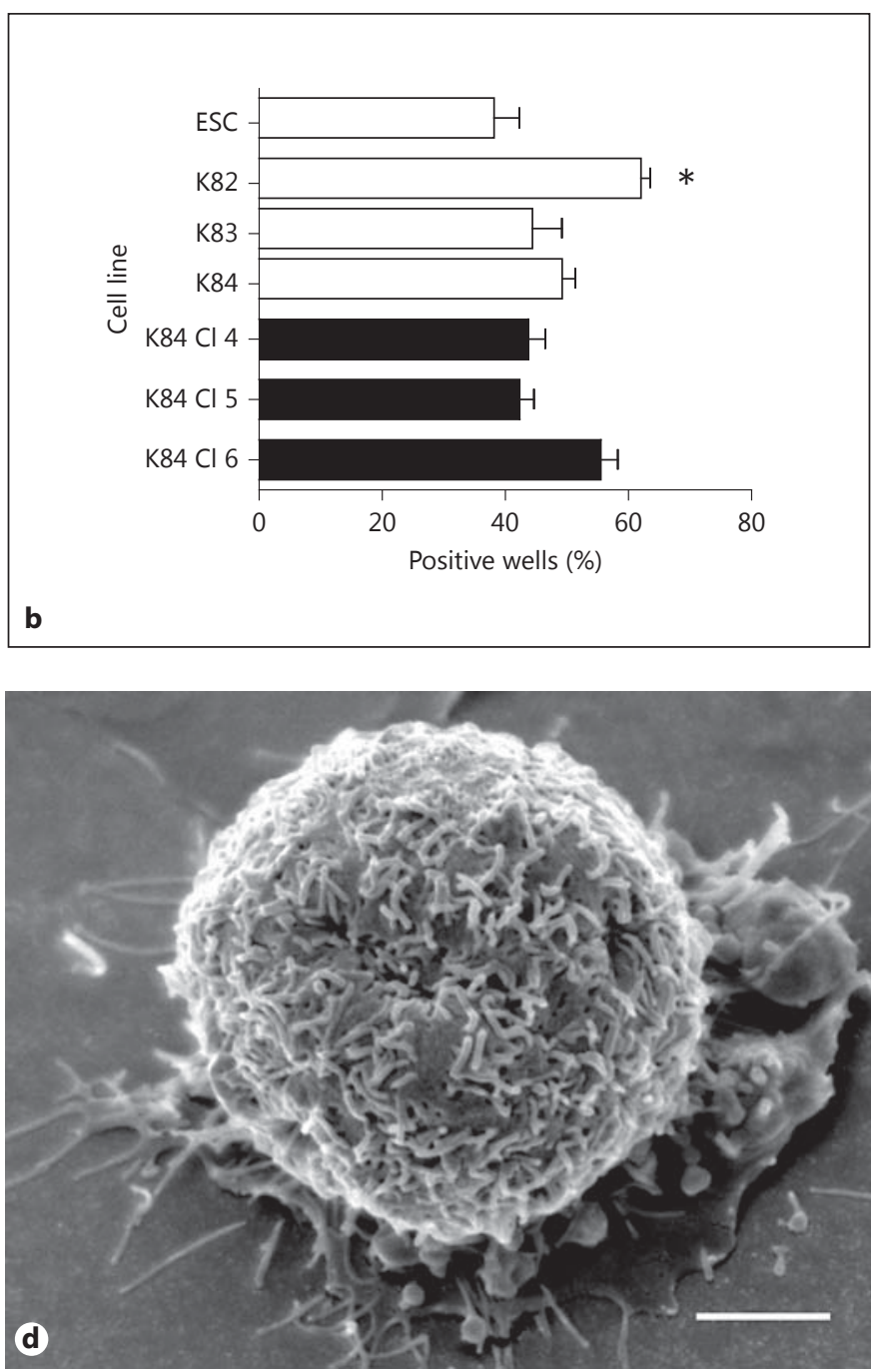

shown. Error bars denote SEM. ${ }^{*} \mathrm{p}<0.05$ vs. ESC and vs. K83. c Cell cycle analysis: representative graph of a K83 cell line is depicted. d Scanning electron microscopy of K82 cell line is shown: rounded cell with numerous microvilli. Bar $=2 \mu \mathrm{m}$.

maintenance of the self-renewal phenotype is further confirmed through retention of a single-cell cloning efficiency of cells from each of the 3 previously sorted individual clonal lines of K84 parent cell line (fig. 1b, dark bars).

We determined the ploidy of cultured AFCL by flowcytometric cell cycle analysis, which showed that 25-32\% of the cells are diploid in G1 phase, $49-51 \%$ are in S phase, and $13-19 \%$ are in G2 phase of the cell cycle; about 5\% of cells had intermediate DNA content. A representative propidium iodide staining of K83 cells is shown in figure 1c. In addition, analysis of growth kinetics of exponen- 


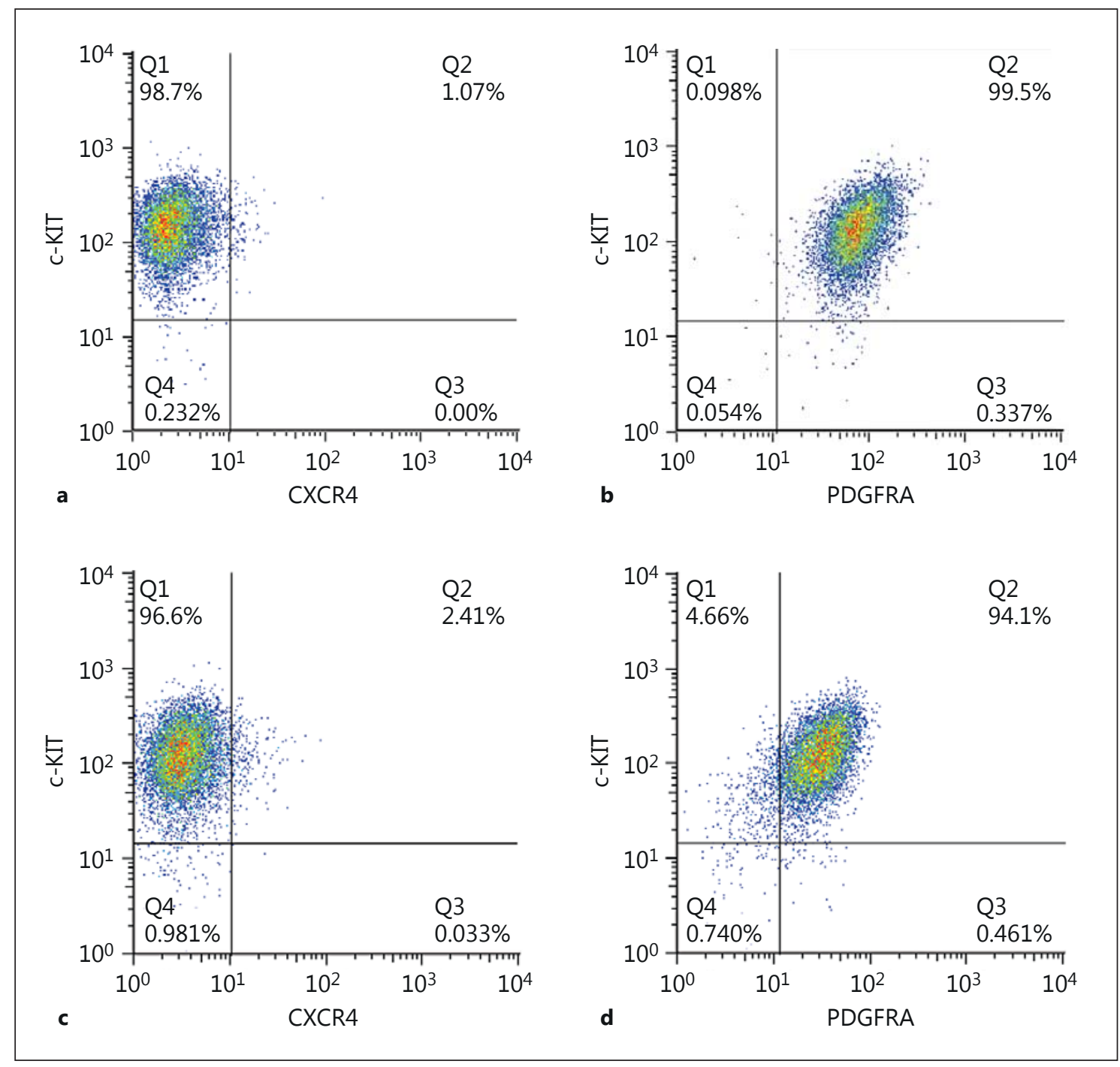

Fig. 2. Flow-cytometric analysis of surface expression of CD117 (c-KIT), CD140a (PDGFRA) and CD184 (CXCR4) on K82 (a, b) and XEN (c, d). Approximately 9,000 DAPI-negative events are shown on each graph.

tially growing AFCL suggests a similar growth rate of all 3 cell lines with an average doubling time of $12.8 \pm 0.5 \mathrm{~h}$ (online suppl. fig. S1).

\section{Morphology and Surface Phenotype of AFCL Is}

Similar to Blastocyst-Derived ExEn Stem Cell Lines

The initial appearance of AFCL was characterized by epithelial colony formation. These colonies are nested inbetween MEF feeders (fig. 1a). When the AFCL are grown on a gelatin-coated surface in the absence of feeder cells, however, they assume several different morphologies, including rounded cells and epithelial sheets, similar to the previously described morphologies of cultured XEN [Ku- nath et al., 2005] (online suppl. fig. S4). Scanning electron microscopic examination of AFCL grown on gelatincoated surfaces showed the presence of rounded cells rich in microvilli, also similar to previously described XEN cells [Kunath et al., 2005] (fig. 1d).

To evaluate phenotypic similarities between AFCL and XEN, we performed flow-cytometric analysis of the surface phenotype of AFCL and XEN10 using a panel of antibodies against surface markers previously shown to be expressed on either AF-derived progenitors (c-KIT) [De Coppi et al., 2007; Moschidou et al., 2012] or definitive endoderm (DE)-derived cells: c-KIT [Orr-Urtreger et al., 1990] and CXCR4 [Yasunaga et al., 2005; Gouon- 
Fig. 3. Analysis of mRNA and protein expression of self-renewal-related genes. a qPCR analysis of mRNA expression in MEF (open white bars), K83 (black bars), XEN10 (yellow bars), and mouse ESC (red bars). Data are normalized to mRNA expression of each gene in CF-1 MEF. Error bars denote SEM. ${ }^{* *} \mathrm{p}<0.01$. b-d Immunofluorescent analysis (top) of LIN28 (b), UTF1 (c), and SALL4 (d) expression in K83, and DAPI nuclear staining (bottom). Bar $=20 \mu \mathrm{m}$.

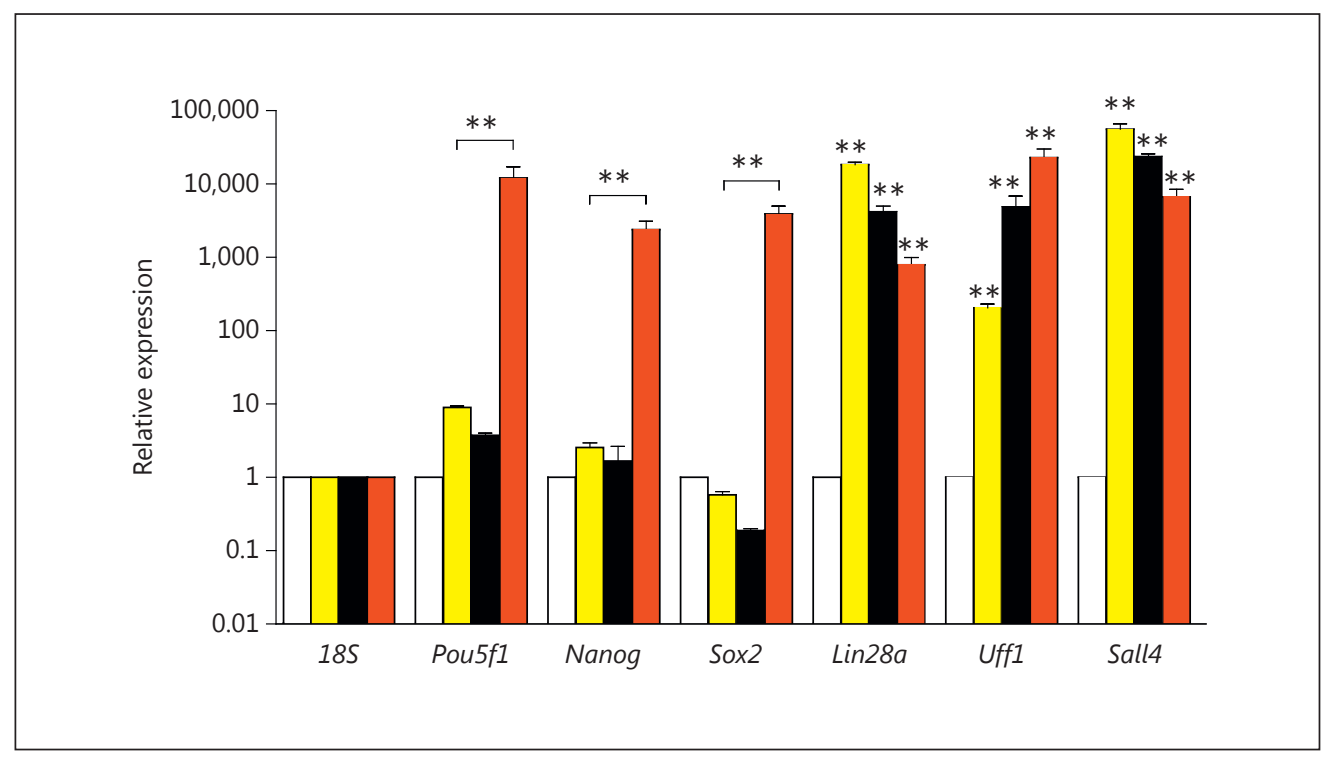

b
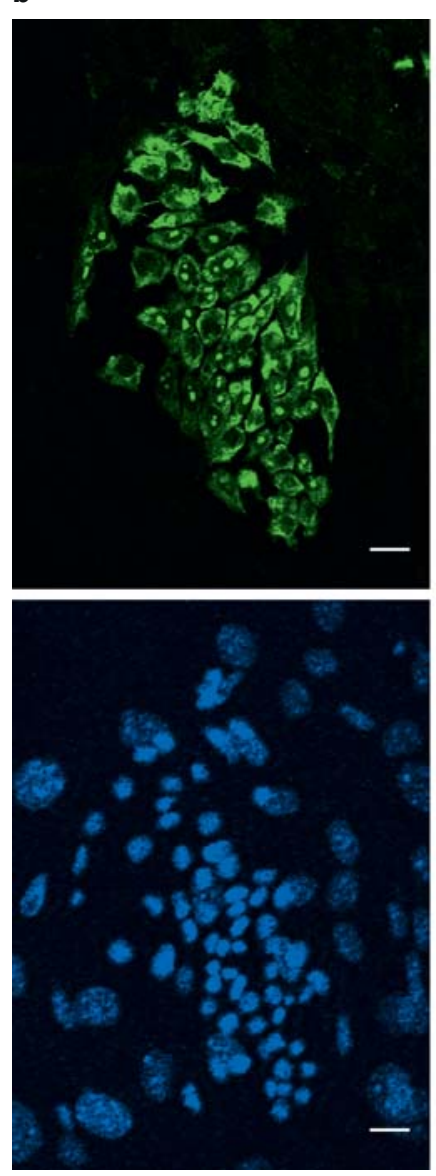

c
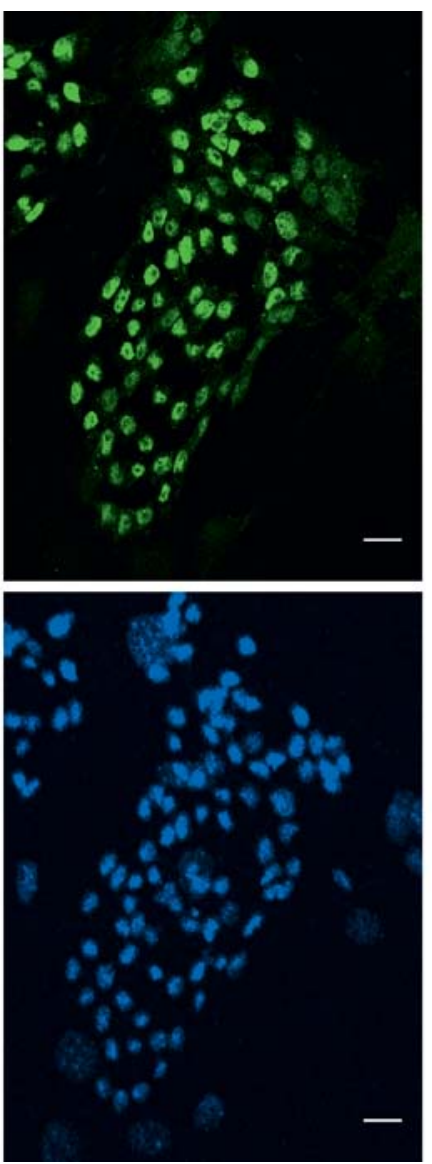

d
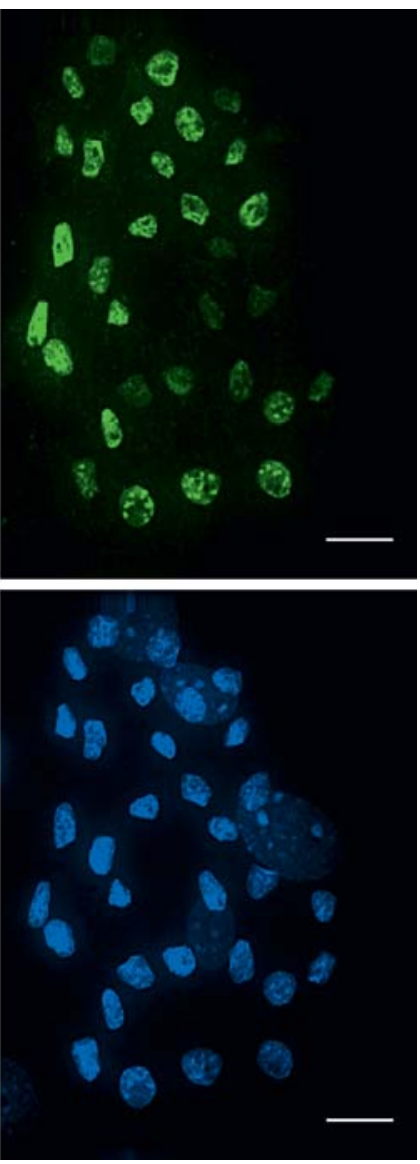
Evans et al., 2006], or XEN, PrE, parietal endoderm (PE) and extraembryonic visceral endoderm (VE) (PDGFRA) [Takakura et al., 1997; Plusa et al., 2008; Artus et al., 2010]. As shown in figure 2, both AFCL (fig. 2b) and XEN (fig. 2d) are c-KIT and PDGFRA double positive. At the same time, both cell types are mostly negative for CXCR4 expression (fig. 2a, c), consistent with the assignment of E11.5-derived AFCL to the XEN lineage. In addition, fluorescence-activated cell sorting (FACS) of the above-mentioned marker expression in early- (online suppl. fig. S2) and late-passage AFCL (online suppl. fig. S3) confirms their phenotypic stability over multiple passages.

Analysis of the Gene Expression Profile of AFCL Confirms That They Belong to the Family of ExEn Stem Cells

To analyze the gene expression pattern potentially associated with self-renewal of AFCL in culture, we initially examined mRNA expression of 6 genes that are notably involved in self-renewal of ESC, including: Pou5f1, Nanog, Sox2, Lin28a, Utf1, and Sall4. Our results showed that both AFCL and XEN10 express levels of Lin28a, Utf1, and Sall4 mRNA comparable to those expressed in ESC (fig. 3a). To verify the corresponding protein expression, we used immunofluorescence analysis of cultured AFCL-K83 stained with LIN28, UTF1, and SALL4 antibodies, and showed that K83 cells express significant levels of the 3 proteins (fig. $3 \mathrm{~b}-\mathrm{d}$ ). Because self-renewal of XEN cells is dependent on Sall4 expression [Lim et al., 2008], we hypothesize that Sall4 expression has a similar importance in AFCL self-renewal, while the specific roles of $\operatorname{Lin} 28$ and Utf1 remain to be tested. Importantly, neither AFCL nor XEN express significant levels of the 3 key pluripotency-related genes, Pou $5 f 1$, Sox2, and Nanog, suggesting that AFCL, like XEN, exist in a lineage-committed self-renewal state.

While both PrE and DE share a significant overlap in gene expression patterns, including Gata4, Gata6, Sox17, and Foxa2, the cells of PrE also express Sox7 [Seguin et al., 2008]. We therefore compared the expression of Gata4, Gata6, Foxa2, Sox17, and Sox7 mRNA in ESC, $\mathrm{XEN}$, and AFCL. As shown in figure 4a, AFCL-K83 express similar levels of PrE lineage genes as XEN cells. In addition, comparative qPCR analysis of Gata6, Gata4, Sox7, and Sox 17 in all 3 AFCL suggests similar expression levels of the 4 PrE-related genes (online suppl. fig. S5A), except that in this experiment K82 appears to have somewhat higher expression of Gata6 compared with K83 and
K84. Protein expression and localization of GATA6 and FOXA2 transcription factors in K83 cells were also confirmed using immunofluorescent analysis of cells grown on culture slides (fig. 4b, c).

Because previous studies support a XEN lineage potential for AFCL, we performed an Illumina mouse whole-genome 6.0 BeadChip-based microarray gene expression analysis on AFCL and compared the obtained data with the gene expression profile of mouse ESC and a previously published microarray data set of three different ExEn-like cell lines [Brown et al., 2010]. Hierarchical clustering of AFCLs, ESC, and ExEn-like cell lines reveals that the whole transcriptome profile of AFCLs is most closely related to blastocyst-derived XEN cells, followed by Pys2 line, while it is well separated from the expression profiles of End 2 line and ESC (fig. 5a). To examine additional similarities and differences between AFCL, XEN, and ESC, we plotted Venn diagrams depicting the number of common and unique genes between the 3 types of cell lines and we observed that the number of common genes between AFCL and XEN is 7,952, compared with the number of commonly expressed genes between AFCL and ESC of 7,042 and between XEN and ESC of 7,131, confirming a closer relationship between AFCL and XEN than between AFCL and ESC (fig. 5b), as suggested by the dendrogram. To more precisely characterize the endodermal potential of AFCL, we examined the expression of genes related to different endodermal subtypes by making a comparative expression heatmap of genes previously shown to be characteristic for various endodermal subtypes, including VE, regional VE, DE, PE, and PrE [Yasunaga et al., 2005; Brown et al., 2010] (fig. 6). These results suggest that all 3 cell lines express a number of markers for PrE, PE, and VE. More specifically, there is a moderate expression of Thbd and Gata4 in K82 compared with K84 cells, and an intermediate level of these 2 genes in K83. All 3 cell lines also express most of the listed markers of $\mathrm{VE}$ and regional VE (excluding Tmprss 2 and $A m n$ ) with slightly lower levels of Ttr, Hnf4a, Foxa3, Fxyd3, and Hhex in K84 compared with K82, while K83 does not express Foxa3 and $D k k 1$. However, the significance of these minor variations in endodermal lineage gene expression is not clear at this time. AFCL also have a notable absence of Cxcr4, a previously described DE marker [Yasunaga et al., 2005], which correlates well with FACS analysis of comparative surface marker expression (fig. 2; online suppl. fig. S2, S3). In summary, AFCL display significant levels of expression of PrE-related genes and more specifically genes related to both $\mathrm{PE}$ and $\mathrm{VE}$, with some variation in 


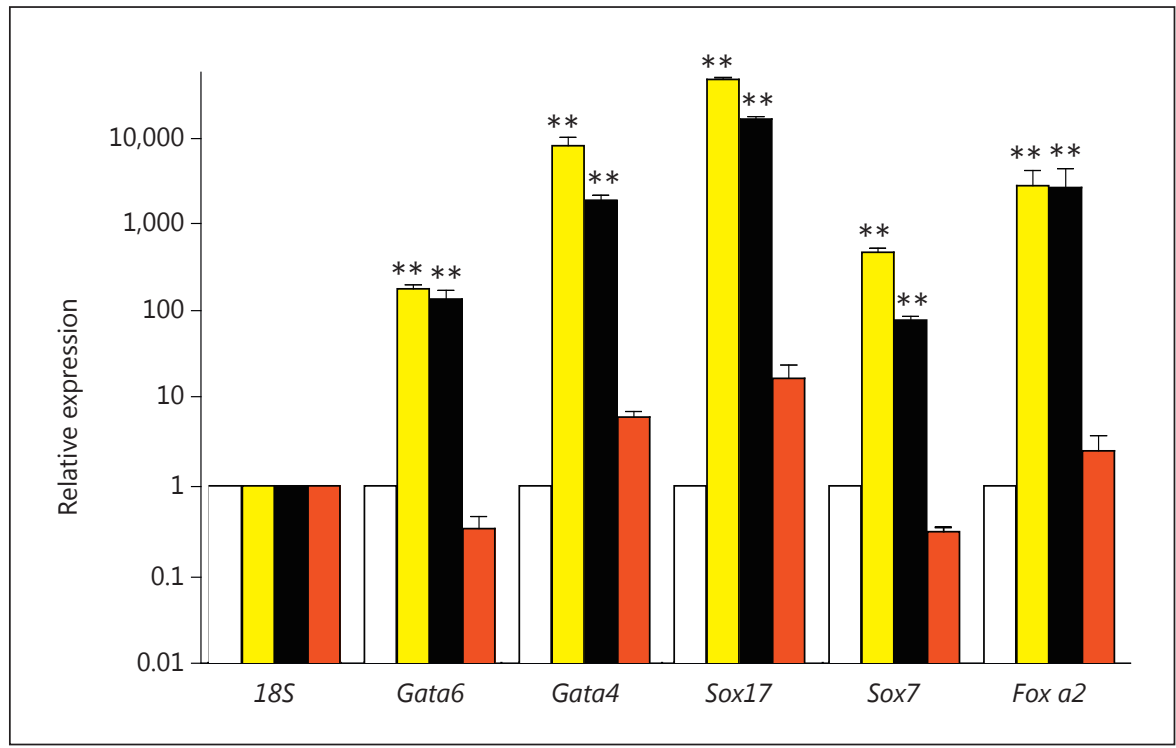

\section{b}
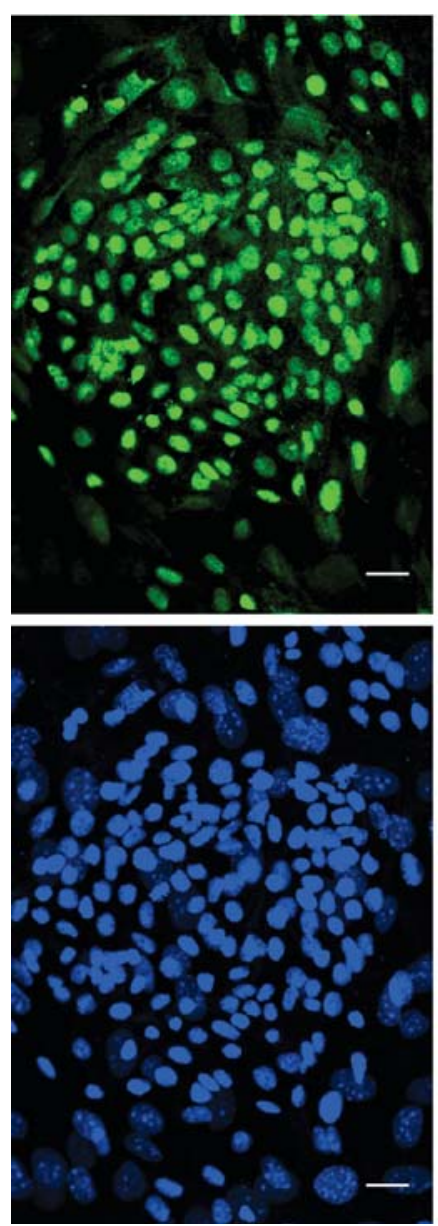

C
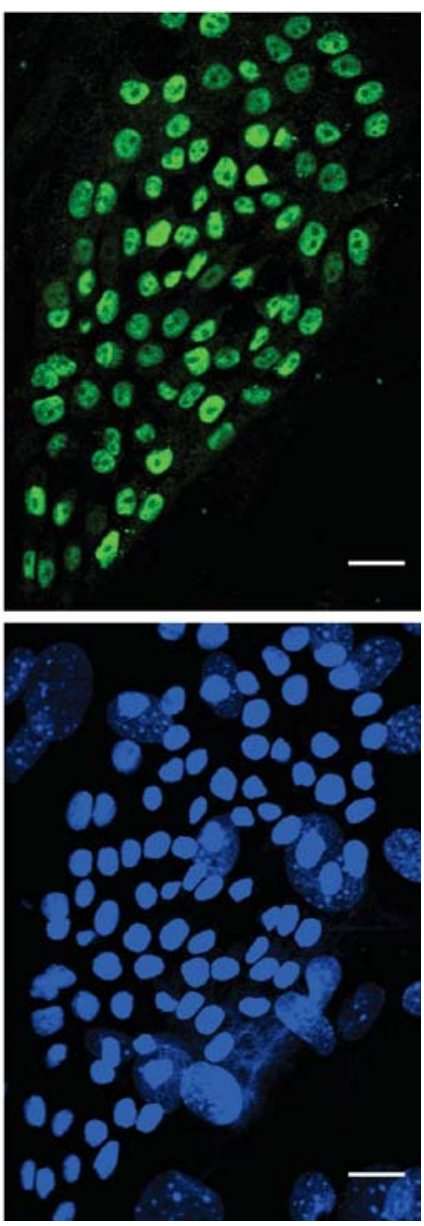

Fig. 4. Analysis of mRNA and protein expression of endoderm lineage genes. a qPCR analysis of mRNA expression in MEF (open white bars), K83 cells (black bars), XEN10 (yellow bars), and mouse ESC (red bars). Data are normalized to mRNA expression of each gene in CF-1 MEF. Error bars denote SEM. ${ }^{* *} \mathrm{p}<0.01$. b, c Immunofluorescent analysis (top) of GATA6 (b) and FOXA2 (c) expression in K83 cells, and DAPI nuclear staining (bottom). Bar $=20 \mu \mathrm{m}$. 


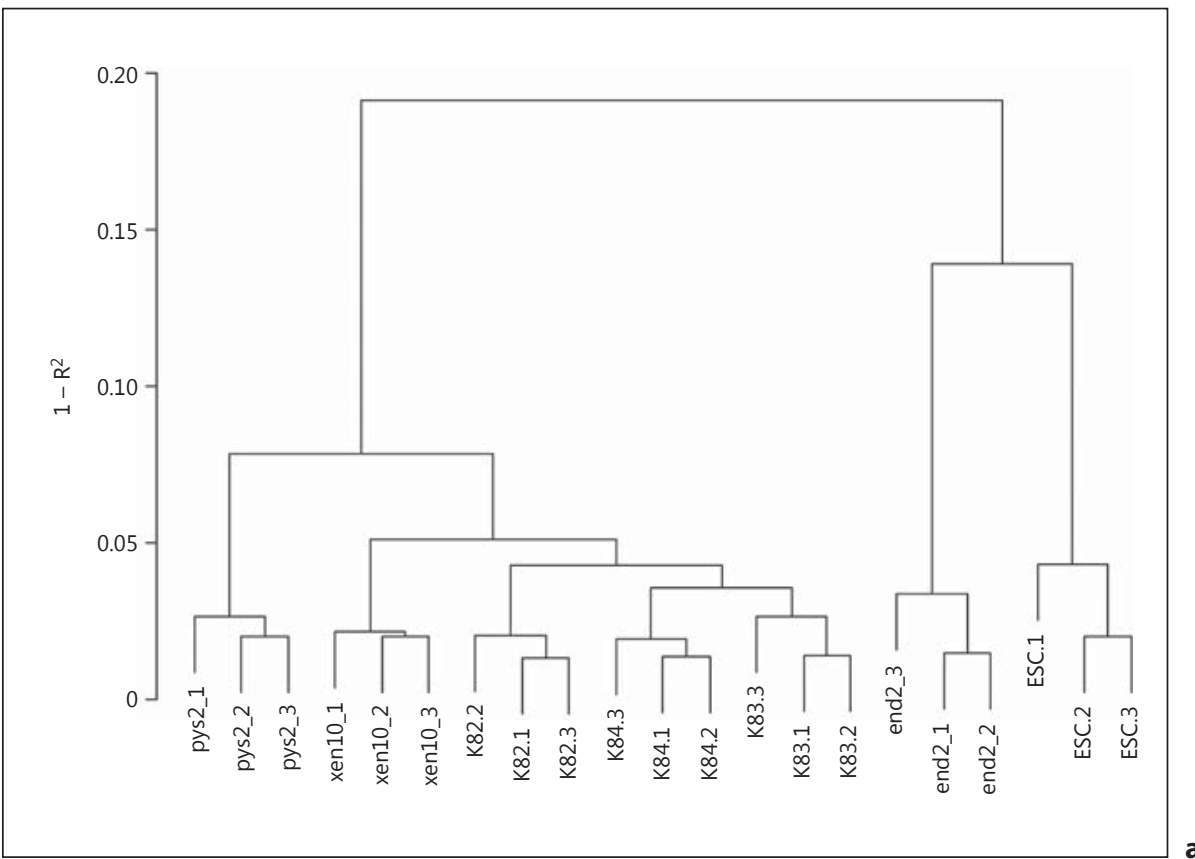

Fig. 5. Hierarchical clustering of AFCL. a Dendrogram for AFCL (K82, K83, and K84), ESC, XEN10, Pys2 and End2 cell lines. Hierarchical clustering included all 45,281 probes and was performed using the 'complete' algorithm and the $1-\mathrm{R}^{2}$ metric. Samples were grouped according to their condition. b Venn diagram depiction of genes whose expression is similar or distinct between the 3 cell types.

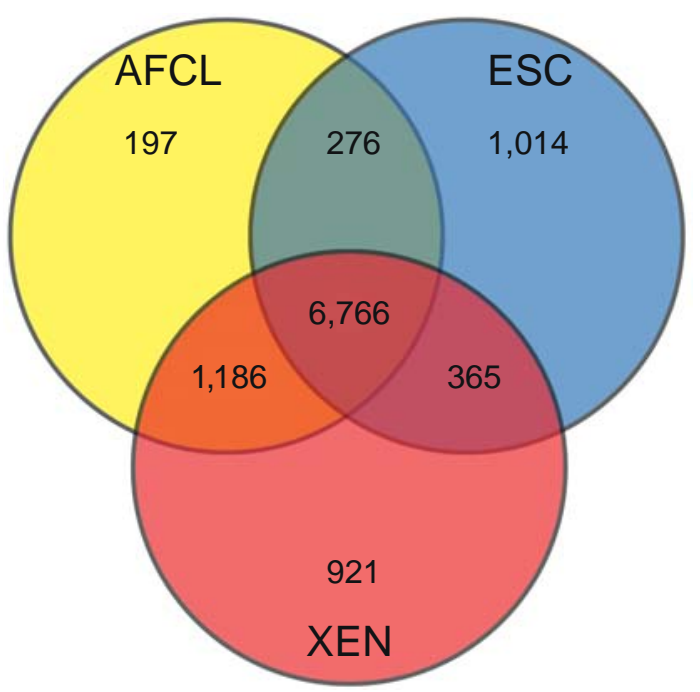

expression levels of individual genes, suggesting that AFCL belong to the ExEn lineage and more closely to XEN cells.

In vitro Differentiation of AFCL Cells Results in the Generation of AFP- and ALB-Producing Cells

To examine the potential for in vitro endodermal lineage commitment of AFCL, we treated these cells with several different cytokines, including BMP4, activin A, epidermal and hepatocyte growth factor, FGF-2, and FGF-4, individually and in combination, followed by measurement of mRNA and protein expression of AFP and ALB as markers of maturing embryonic and ExEn lineages. The most efficient differentiation protocol was based on a previously published study [Yasunaga et al., 2005] and it required the presence of BMP4 during both 
stages of differentiation (data not shown). The differentiation resulted in significant upregulation of $A f p$ and $A l b$ mRNA (fig. 7a) and protein (fig. 7b), consistent with the known role of BMP4 in differentiation of blastocyst-derived XEN into AFP-expressing VE [Artus et al., 2012; Paca et al., 2012]. Comparative qPCR analysis of $A f p$ and $A l b$ expression before and after differentiation in all 3 AFCL is shown in online supplementary figure S5B. These results confirm that all 3 AFCL are capable of in vitro differentiation in the presence of BMP4. In addition, it can also be noted that K82 has a slightly higher efficiency of differentiation (suggested by the difference in $A f p$ and $A l b$ levels between the undifferentiated and differentiated state) compared with the other 2 cell lines, which did not reach the level of statistical significance (online suppl. fig. S5B).

\section{AFCL Generate PrE Tumors in vivo}

The teratoma formation assay is a standard assay for the multilineage potential of pluripotent cells in vivo. We therefore injected cells from either AFCL or ESC (positive control) intramuscularly into immunodeficient mice and observed teratoma formation in the animals. ESCderived tumors appeared after approximately 3 weeks, but AFCL-derived tumors required 6-8 weeks to appear. Histological analysis confirmed the multilineage properties of the control ESC-derived teratoma (data not shown). AFCL-derived tumors, however, had a significantly different appearance from the ESC-derived tumors, with a glandular appearance (fig. 8) and a significant amount of interglandular amorphous matrix, suggestive of an immature endodermal lineage origin. AFCL tumor cells also expressed significant levels of AFP (fig. 8b). Detailed histological examination of AFCL tumors did not yield any evidence of definitive ectodermal, mesodermal, or endodermal differentiation. Hence, AFC likely represent PrE progenitors with limited potential for in vivo PrE differentiation during heterotopic transplantation.

\section{Discussion}

Development of cell replacement therapy for degenerative diseases is one of the most eagerly sought goals of stem cell research. A requirement for this goal is the generation of pure populations of progenitor cells with extensive ability for expansion. While differentiation of ESC into lineage-committed cells could fulfill the criteria for clinical application, the requirement for embryo de-

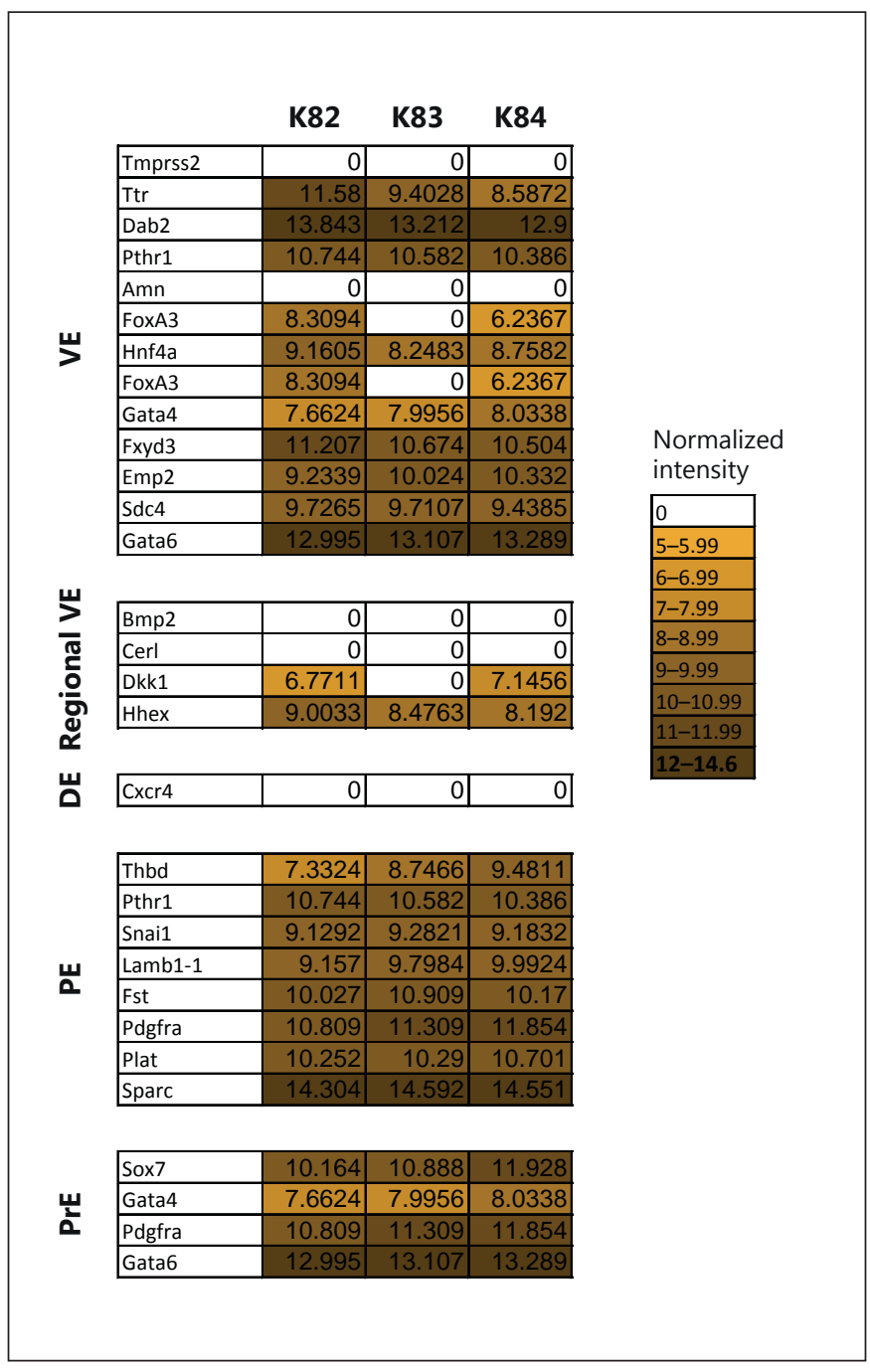

Fig. 6. Heat map of genes characteristic for different endodermal subtypes. Normalized data from the Illumina microarray for genes previously described as specifically expressed in each endodermal subtype. Intensity value was depicted as zero if the $\mathrm{p}$ value detected was $>0.01$.

struction to generate new ESC lines raises substantial ethical and religious barriers to implementation. iPSC are an alternative source of pluripotent cells for lineage differentiation [Takahashi et al., 2007]. Although these cells avoid many of the ethical and availability drawbacks associated with the use of ESC, concerns exist about their true therapeutic value due to the presence of oncogenic viruses and proteins used to immortalize the cells, the low efficiency of iPSC line generation [Sun et al., 2010], and their limited and unpredictable differentiation potential [Feng et al., 2010]. We therefore determined whether AF could 


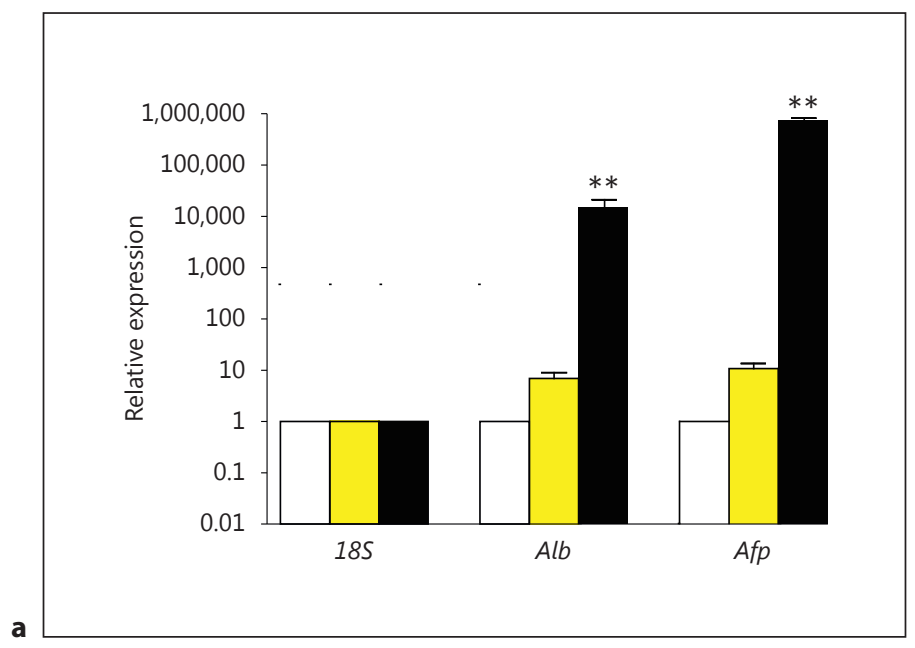

Fig. 7. Analysis of mRNA and protein expression of $A l b$ and $A f p$ after in vitro differentiation of K82 cells. a qPCR analysis of mRNA expression in MEF (open white bars), K82 cells before differentiation (yellow bars) and K82 cells after differentiation (black bars). Data are normalized to mRNA expression of $A f p$ and $A l b$ in CF-1 MEF. Error bars denote SEM. ${ }^{* *} \mathrm{p}<0.01$. b, c Immunofluorescent analysis of ALB (b) and AFP expression (c) in differentiated K82 cells. DAPI nuclear staining is shown in blue. $\mathrm{Bar}=20 \mu \mathrm{m}$.

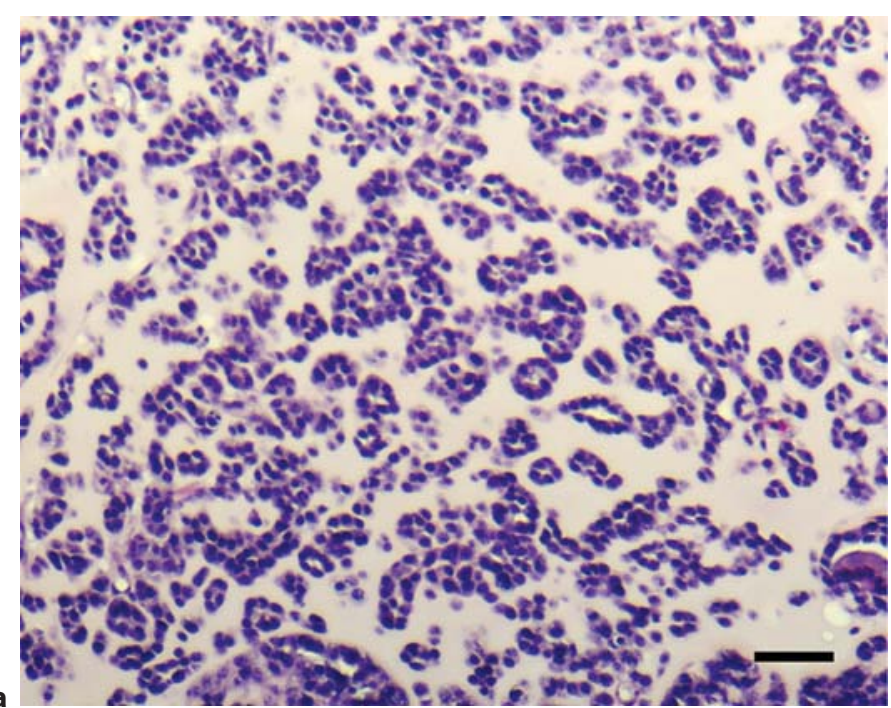

Fig. 8. Histological and immunohistochemical analysis of tumors formed by K82 cells. Bar $=50 \mu \mathrm{m}$. a HE staining of a tumor section. b Immunoperoxidase staining of an anti-AFP antibody-labeled
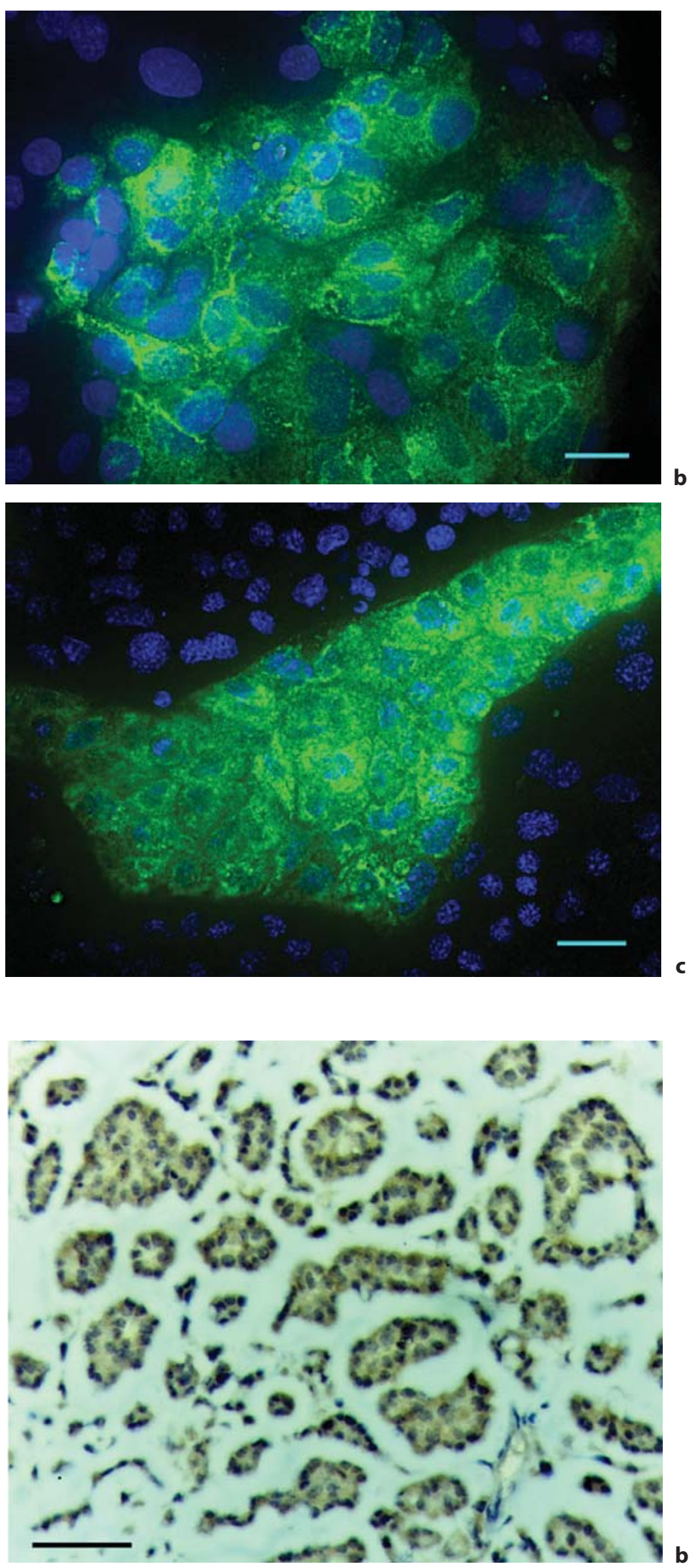

tumor section counterstained with hematoxylin. Antigen-positive areas are labeled with brown color. 
be an alternative source of committed progenitor cells able to give rise to stable self-renewing cell lines that could be used in subsequent cell therapies.

AF contains several types of stem cells, including MSCs and c-KIT+ AFSC. Human AF-derived MSCs have been consistently isolated from AF and have been previously well characterized as positive for surface expression of CD73, CD105, CD44, CD29, CD90, CD13, CD10, CD71, and several other markers [Klein and Fauza, 2011]. These cells are capable of chondrogenic [Kunisaki et al., 2006] and osteogenic [Turner et al., 2012] differentiation. However, wider application of MSC in regenerative medicine applications may be limited by their finite life span and eventual loss of their stem cell properties during prolonged culture [Liu et al., 2009]. Alternatively, we considered c-KIT+ cells an appropriate candidate for our studies since c-KIT + AFC have previously been described as capable of limited self-renewal and multilineage differentiation [De Coppi et al., 2007; Moschidou et al., 2012]. As the generation of a stable cell line from progenitor cells likely involves overcoming of a significant epigenetic barrier [Surani et al., 2007], we hypothesized that the culture conditions previously shown to convert c-KIT+ primordial germ cells to self-renewing c-KIT+ EGC lines may also facilitate such conversion of AFC [Matsui et al., 1992; Resnick et al., 1992; Shamblott et al., 1998].

An important aspect of the generation of stem cell lines in vitro is maintenance of cultured cells in an in vitro 'niche' environment [Davey and Zandstra, 2006]. To establish the key components of the initial AFCL culture that stimulated cell line formation, we varied several culture parameters, including growth factor composition and feeder cell type. The resulting conclusion is that utilization of irradiated STO cells is critical for achieving reproducible success in cell line generation. Application of commonly used CF-1 feeder cells was unsuccessful, resulted in a gradual decrease in the total cell number in culture, and subsequent failure to establish stable cell lines. The exact mechanism of benefit from STO cells is not clear, but it is likely related to differences in the amount and the type of cytokines and/or extracellular signaling molecules, including activin A (high in CF-1), hepatocyte growth factor (high in STO), IL-6 (high in CF1), SCF (high in STO), and others [Talbot et al., 2012]. Since AFCL are consistently c-KIT+ and fail to be generated on CF- 1 cells, it is possible that c-KIT-SCF interaction is critical for AFCL generation. However, because we used an identical derivation medium (containing exogenous soluble SCF) with either STO or CF-1 feeders, we hypothesize that it is the transmembrane SCF that may

PrE Cell Lines from Mouse AF play an important role in AFCL derivation based on previously shown differential effects of soluble and transmembrane SCF in other cell types [Ashman, 1999]. Importantly, comparison of derivation conditions for blastocyst-derived XEN cells [Kunath et al., 2005] and our results with AFCL suggests that the more advanced developmental stage of AFCL require more elaborate culture conditions for cell line generation, as blastocyst-derived XEN can be successfully generated even on mitotically inactivated primary fibroblast feeders.

Self-renewal is one of the two key properties of stemness. The most detailed studies of stem cell self-renewal mechanisms have been performed in the ESC system where a core self-renewal machinery was described consisting of Pou5f1, Sox2, and Nanog genes [Boyer et al., 2005; Mallanna and Rizzino, 2012]. The proteins coded by the 3 genes maintain self-renewal through regulation of a large transcriptional network that includes targets such as Sall4 [Lim et al., 2008], Lin28 [Shyh-Chang and Daley, 2013], Utf1 [Laskowski and Knoepfler, 2012], and others. To examine the genes potentially involved in selfrenewal of AFCL, we analyzed the expression of the above-mentioned genes and discovered that the self-renewal of AFCL, like XEN, can be maintained in the absence of gene expression of the core self-renewal network of ESC. Further analysis of the AFCL gene expression profile suggests that AFCL, like XEN, have a high expression of Sall4, Lin28, and Utf1, which may be able to participate in an XEN-type self-renewal gene network. Importantly, previous studies described a critical role for Sall4 in XEN self-renewal [Lim et al., 2008], giving support to the above hypothesis. However, additional studies will be required to test the dependence of AFCL self-renewal on Sall4, Utf1, and/or Lin28.

The majority of previously examined mouse XEN cell lines exhibit several characteristics of PE in culture [Kunath et al., 2005; Brown et al., 2010; Paca et al., 2012]. These include poor maintenance of epithelial appearance during extended culture and predominant contribution to $\mathrm{PE}$ after blastocyst injection, which is suggestive of their predominant $\mathrm{PE}$ differentiation potential. However, rat XEN cell lines appear to have a more balanced VE versus PE differentiation potential resulting in significant contribution of these cells to extraembryonic VE upon blastocyst injection [Debeb et al., 2009] and also in activation of the PE program with forskolin and the VE program with a small-molecule GSK3 inhibitor [Chuykin et al., 2013]. To examine the in vitro differentiation potency of AFCL, we began with an observation that AFCL grown on gelatin surface have growth characteristics similar to 
XEN, including ineffective maintenance of epithelial properties, which is consistent with the PE potential [Hogan and Tilly, 1981]. Furthermore, statistical analysis of the whole transcriptome profile of AFCL suggested that it correlates most closely with the profile of blastocystderived XEN cells and ExEn-like Pys 2 cells, and this analysis showed that AFCL express transcripts of both PE and VE, suggestive of their bipotency. However, when we examined the gene expression profile of K82 cells cultured for 2-3 weeks after reaching confluence, using a qPCR array, we observed significant induction of Afp expression (data not shown), consistent with VE-type differentiation, as Afp is mainly expressed in VE and not PE [Dziadek and Adamson, 1978]. To confirm our hypothesis of the VE differentiation potential of AFCL, we tested several different cytokines and observed that BMP4 is critical for induction of AFP and ALB expression, suggesting that BMP4 can induce extraembryonic VE [Yasunaga et al., 2005] in AFCL, which is consistent with published reports describing BMP4-mediated VE induction in blastocyst-derived XEN [Artus et al., 2012; Paca et al., 2012]. Further analysis of in vitro $A f p$ and $A l b$ expression in all 3 AFCL, submitted to an abbreviated differentiation protocol, confirmed that they are capable of extraembryonic VE-type differentiation with somewhat different efficiencies. The molecular basis for these differences is not clear, but it may come from differential expression of a number of PE- and/or VE-specific genes, as evidenced from microarray analysis, and/or a difference in Gata6 expression (higher in K82), as observed during comparative qPCR analysis. Of note, the same experiment also shows that the basic AFCL maintenance medium can be used to propagate cells with a higher baseline expression level of $A f p$ and $A l b$, suggesting that modest increase in the expression of VE-type markers does not interfere with cell line propagation. The elevated levels of $A f p$ and $A l b$ are likely related to a different lot of ESC-tested FBS used for routine maintenance of AFCL, as previous studies demonstrated the presence of BMP-type activity in FBS [Kodaira et al., 2006] as well as a significant lot-to-lot variability in BMP content of FBS [Herrera and Inman, 2009]. To examine the in vivo differentiation potential of AFCL, we analyzed the histological characteristics of AFCL-derived tumors and observed endodermal sinus-type glandular clusters that also showed presence of AFP, which can suggest a potentially significant in vivo VE differentiation potential of AFCL. However, further studies would be required to confirm this hypothesis because Afp may be expressed in tissues other than VE [Yasunaga et al., 2005]. In summary, AFCL appear to display a context- related VE or PE differentiation potential similar to previously studied blastocyst-derived XEN cell lines.

The origin of AFC capable of generating PrE cell lines in vitro is currently unknown. Such cell lines have mostly been generated from blastocyst-stage embryos in the past [Kunath et al., 2005]. However, a recent report also suggested that PrE cell lines can be generated from adult rat bone marrow [Roelandt et al., 2010]. AF may therefore receive $\operatorname{PrE}$ endoderm progenitors through a transient communication between amniotic and yolk sacs via a transient neurenteric canal [Ozek et al., 2008]. Alternatively, XEN cell lines may derive from PrE-derived cells in fetal gut [Kwon et al., 2008], which are then released into AF through regular emptying of fetal gut contents, an activity observed in both early and mid-gestation human fetuses [Kimble et al., 1999]. A less likely possibility is transdifferentiation of definitive endodermal progenitors into XEN cell lines when maintained under the culture conditions described above

In this report, we describe the derivation of AFCL from AF of the $129 \mathrm{X} 1 / \mathrm{SvJ}$ mouse strain. This strain was purposefully chosen as the initial donor of AF because of previous reports of high permissiveness for ESC derivation of the same mouse strain [Brook and Gardner, 1997]. XEN were initially derived from several different mouse strains, including PO, ICR and 129 [Kunath et al., 2005], as well as from several different rat strains [Debeb et al., 2009], without the use of small-molecule inhibitors, which were required for efficient derivation of ESC from various mouse and rat strains [Blair et al., 2011]. This suggests that AFCL could potentially be established from different mouse and rat strains with minimal protocol modification. Importantly, ExEn cell lines have not yet been established from human blastocysts. The information we have about human PrE lineage mostly comes from studies on PrE cells that arise during human ESC and iPSC differentiation [Takayama et al., 2011; Feng et al., 2012]. Interestingly, a recent report describes a population of c$\mathrm{KIT}+$ cells isolated from first-trimester human AF that express Sox7 [Moschidou et al., 2012], a key factor in the development of PE. Whether these human AFC represent human counterparts of mouse AFCL-generating progenitors remains to be studied.

In summary, we have demonstrated that culture of AFderived progenitor cells in culture conditions that support self-renewal can generate phenotypically stable self-renewing cell lines of the PrE lineage. Our approach has an excellent reproducibility of cell line derivation and the phenotypic stability of AFCL. These findings, together with the previously published results that suggest the presence 
of lineage plasticity in cells of PrE, allowing it to contribute to embryonic tissue at different stages of development [Kwon et al., 2008; Grabarek et al., 2012], would make potential human counterparts of such cell lines a candidate for banking and subsequent manipulation to prepare cell replacement therapies for regenerative medicine.

\section{Acknowledgments}

We thank Dr. Malcolm K. Brenner for critically reviewing the paper and for helpful discussions; Dr. Leslie Silberstein for helpful discussions; Chris Threeton, Tatiana Goltsova, and Amos Gaikwad of the Texas Children's Hospital Flow Cytometry Core Facility for help with cell sorting experiments; Tuan Tran of the UT
Health Sciences Center at Houston for microarray analysis; Laura Liles of the BCM Microarray Core for help with microarray data analysis; Lihong $\mathrm{Bu}$ of the IDDRC Cellular Imaging Core for help with confocal microscopy; James Broughman of the Integrated Microscopy Core Facility at BCM for help with deconvolution microscopy; Kemi Cui of the Advanced Cellular and Tissue Microscopy Core Laboratory at TMHRI for help with confocal microscopy; Dita Mayerova for help with the teratoma assay; Kenneth Dunner of the UTMDACC High Resolution Electron Microscopy Facility (supported by Institutional core grant No. CA16672) for sample preparation and imaging, and Charlotte Su and Keri Watson for technical assistance. This work was supported by NHLBI K08 HL088508 through the Brigham and Women's Hospital and The Methodist Hospital, and the Joint Program in Transfusion Medicine at the Brigham and Women's Hospital, Boston Children's Hospital, and Dana-Farber Cancer Institute, and The Methodist Hospital Research Institute institutional funding.

\section{References}

Artus, J., P. Douvaras, A. Piliszek, J. Isern, M.H. Baron, A.K. Hadjantonakis (2012) BMP4 signaling directs primitive endoderm-derived XEN cells to an extraembryonic visceral endoderm identity. Dev Biol 361: 245-262.

Artus, J., J.J. Panthier, A.K. Hadjantonakis (2010) A role for PDGF signaling in expansion of the extra-embryonic endoderm lineage of the mouse blastocyst. Development 137: 33613372.

Ashman, L.K. (1999) The biology of stem cell factor and its receptor C-kit. Int J Biochem Cell Biol 31: 1037-1051.

Blair, K., J. Wray, A. Smith (2011) The liberation of embryonic stem cells. PLoS Genet 7: e1002019.

Boyer, L.A., T.I. Lee, M.F. Cole, S.E. Johnstone, S.S. Levine, J.P. Zucker, M.G. Guenther, R.M. Kumar, H.L. Murray, R.G. Jenner, D.K. Gifford, D.A. Melton, R. Jaenisch, R.A. Young (2005) Core transcriptional regulatory circuitry in human embryonic stem cells. Cell 122: 947-956.

Brons, I.G., L.E. Smithers, M.W. Trotter, P. RuggGunn, B. Sun, S.M. Chuva de Sousa Lopes, S.K. Howlett, A. Clarkson, L. Ahrlund-Richter, R.A. Pedersen, L. Vallier (2007) Derivation of pluripotent epiblast stem cells from mammalian embryos. Nature 448: 191-195.

Brook, F.A., R.L. Gardner (1997) The origin and efficient derivation of embryonic stem cells in the mouse. Proc Natl Acad Sci USA 94: 57095712.

Brown, K., S. Legros, J. Artus, M.X. Doss, R. Khanin, A.K. Hadjantonakis, A. Foley (2010) A comparative analysis of extra-embryonic endoderm cell lines. PloS One 5: e12016.

Chuykin, I., H. Schulz, K. Guan, M. Bader (2013) Activation of the PTHRP/adenylate cyclase pathway promotes differentiation of rat XEN cells into parietal endoderm, whereas Wnt/beta-catenin signaling promotes differentiation into visceral endoderm. J Cell Sci 126: 128-138.
Davey, R.E., P.W. Zandstra (2006) Spatial organization of embryonic stem cell responsiveness to autocrine gp130 ligands reveals an autoregulatory stem cell niche. Stem Cells 24: 25382548.

De Coppi, P., G. Bartsch, Jr., M.M. Siddiqui, T. $\mathrm{Xu}$, C.C. Santos, L. Perin, G. Mostoslavsky, A.C. Serre, E.Y. Snyder, J.J. Yoo, M.E. Furth, S. Soker, A. Atala (2007) Isolation of amniotic stem cell lines with potential for therapy. Nat Biotechnol 25: 100-106.

Debeb, B.G., V. Galat, J. Epple-Farmer, S. Iannaccone, W.A. Woodward, M. Bader, P. Iannaccone, B. Binas (2009) Isolation of Oct4-expressing extraembryonic endoderm precursor cell lines. PLoS One 4: e7216.

Dziadek, M., E. Adamson (1978) Localization and synthesis of alphafoetoprotein in post-implantation mouse embryos. J Embryol Exp Morphol 43: 289-313.

Evans, M.J., M.H. Kaufman (1981) Establishment in culture of pluripotential cells from mouse embryos. Nature 292: 154-156.

Feng, Q., S.J. Lu, I. Klimanskaya, I. Gomes, D. Kim, Y. Chung, G.R. Honig, K.S. Kim, R. Lanza (2010) Hemangioblastic derivatives from human induced pluripotent stem cells exhibit limited expansion and early senescence. Stem Cells 28: 704-712.

Feng, X., J. Zhang, K. Smuga-Otto, S. Tian, J. Yu, R. Stewart, J.A. Thomson (2012) Protein kinase $\mathrm{C}$ mediated extraembryonic endoderm differentiation of human embryonic stem cells. Stem Cells 30: 461-470.

Gosden, C.M. (1983) Amniotic fluid cell types and culture. Br Med Bull 39: 348-354.

Gouon-Evans, V., L. Boussemart, P. Gadue, D. Nierhoff, C.I. Koehler, A. Kubo, D.A. Shafritz, G. Keller (2006) BMP-4 is required for hepatic specification of mouse embryonic stem cell-derived definitive endoderm. Nat Biotechnol 24: 1402-1411.
Grabarek, J.B., K. Zyzynska, N. Saiz, A. Piliszek, S. Frankenberg, J. Nichols, A.K. Hadjantonakis, B. Plusa (2012) Differential plasticity of epiblast and primitive endoderm precursors within the ICM of the early mouse embryo. Development 139: 129-139.

Gray, F.L., C.G. Turner, A. Ahmed, C.E. Calvert, D. Zurakowski, D.O. Fauza (2012) Prenatal tracheal reconstruction with a hybrid amniotic mesenchymal stem cells-engineered construct derived from decellularized airway. J Pediatr Surg 47: 1072-1079.

Herrera, B., G.J. Inman (2009) A rapid and sensitive bioassay for the simultaneous measurement of multiple bone morphogenetic proteins. Identification and quantification of BMP4, BMP6 and BMP9 in bovine and human serum. BMC Cell Biol 10: 20.

-Hogan, B.L., R. Tilly (1981) Cell interactions and endoderm differentiation in cultured mouse embryos. J Embryol Exp Morphol 62: 379394.

-Jaenisch, R., R. Young (2008) Stem cells, the molecular circuitry of pluripotency and nuclear reprogramming. Cell 132: 567-582.

Johnson, W.E., C. Li, A. Rabinovic (2007) Adjusting batch effects in microarray expression data using empirical Bayes methods. Biostatistics 8: 118-127.

Kaviani, A., K. Guleserian, T.E. Perry, R.W. Jennings, M.M. Ziegler, D.O. Fauza (2003) Fetal tissue engineering from amniotic fluid. J Am Coll Surg 196: 592-597.

Kimble, R.M., B. Trudenger, D. Cass (1999) Fetal defaecation: is it a normal physiological process? J Paediatr Child Health 35: 116-119.

Klein, J.D., D.O. Fauza (2011) Amniotic and placental mesenchymal stem cell isolation and culture. Methods Mol Biol 698: 75-88. 
Kodaira, K., M. Imada, M. Goto, A. Tomoyasu, T. Fukuda, R. Kamijo, T. Suda, K. Higashio, T. Katagiri (2006) Purification and identification of a BMP-like factor from bovine serum. Biochem and Biophys Res Commun 345: 1224-1231.

Kunath, T., D. Arnaud, G.D. Uy, I. Okamoto, C. Chureau, Y. Yamanaka, E. Heard, R.L. Gardner, P. Avner, J. Rossant (2005) Imprinted Xinactivation in extra-embryonic endoderm cell lines from mouse blastocysts. Development 132: 1649-1661.

Kunisaki, S.M., M. Armant, G.S. Kao, K. Stevenson, H. Kim, D.O. Fauza (2007) Tissue engineering from human mesenchymal amniocytes: a prelude to clinical trials. J Pediatr Surg 42: 974-979, discussion 979-980.

Kunisaki, S.M., R.W. Jennings, D.O. Fauza (2006) Fetal cartilage engineering from amniotic mesenchymal progenitor cells. Stem Cells Dev 15: 245-253.

Kwon, G.S., M. Viotti, A.K. Hadjantonakis (2008) The endoderm of the mouse embryo arises by dynamic widespread intercalation of embryonic and extraembryonic lineages. Dev Cell 15: 509-520.

-Laskowski, A.I., P.S. Knoepfler (2012) Utf1: Goldilocks for ESC bivalency. Cell Stem Cell 11: $732-734$.

Lim, C.Y., W.L. Tam, J. Zhang, H.S. Ang, H. Jia, L. Lipovich, H.H. Ng, C.L. Wei, W.K. Sung, P. Robson, H. Yang, B. Lim (2008) Sall4 regulates distinct transcription circuitries in different blastocyst-derived stem cell lineages. Cell Stem Cell 3: 543-554.

Liu, T.M., Y.N. Wu, X.M. Guo, J.H. Hui, E.H. Lee, B. Lim (2009) Effects of ectopic Nanog and Oct4 overexpression on mesenchymal stem cells. Stem Cells Dev 18: 1013-1022.

Mallanna, S.K., A. Rizzino (2012) Systems biology provides new insights into the molecular mechanisms that control the fate of embryonic stem cells. J Cell Physiol 227: 27-34.

Martin, G.R. (1981) Isolation of a pluripotent cell line from early mouse embryos cultured in medium conditioned by teratocarcinoma stem cells. Proc Natl Acad Sci USA 78: 76347638.

Matsui, Y., K. Zsebo, B.L. Hogan (1992) Derivation of pluripotential embryonic stem cells from murine primordial germ cells in culture. Cell 70: 841-847.

Moschidou, D., K. Drews, A. Eddaoudi, J. Adjaye, P. De Coppi, P.V. Guillot (2013) Molecular signature of human amniotic fluid stem cells during fetal development. Curr Stem Cell Res Ther 8: 73-81.
Moschidou, D., S. Mukherjee, M.P. Blundell, K. Drews, G.N. Jones, H. Abdulrazzak, B. Nowakowska, A. Phoolchund, K. Lay, T.S. Ramasamy, M. Cananzi, D. Nettersheim, M. Sullivan, J. Frost, G. Moore, J.R. Vermeesch, N.M. Fisk, A.J. Thrasher, A. Atala, J. Adjaye, H. Schorle, P. De Coppi, P.V. Guillot (2012) Valproic acid confers functional pluripotency to human amniotic fluid stem cells in a transgene-free approach. Mol Ther 20: 1953-1967.

Mullen, P. (2004) Flow cytometric DNA analysis of human cancer cell lines. Methods Mol Med 88: 247-255.

Orr-Urtreger, A., A. Avivi, Y. Zimmer, D. Givol, Y. Yarden, P. Lonai (1990) Developmental expression of c-kit, a proto-oncogene encoded by the W locus. Development 109: 911-923.

Ozek, M.M., G. Cinalli, W.J. Maixner (2008) Spina Bifida: Management and Outcome. Berlin, Springer.

Paca, A., C.A. Seguin, M. Clements, M. Ryczko, J. Rossant, T.A. Rodriguez, T. Kunath (2012) BMP signaling induces visceral endoderm differentiation of XEN cells and parietal endoderm. Dev Biol 361: 90-102.

Plusa, B., A. Piliszek, S. Frankenberg, J. Artus, A.K. Hadjantonakis (2008) Distinct sequential cell behaviours direct primitive endoderm formation in the mouse blastocyst. Development 135: 3081-3091.

Resnick, J.L., L.S. Bixler, L. Cheng, P.J. Donovan (1992) Long-term proliferation of mouse primordial germ cells in culture. Nature 359: 550-551.

Roelandt, P., K.A. Pauwelyn, P. Sancho-Bru, K. Subramanian, B. Bose, L. Ordovas, K. Vanuytsel, M. Geraerts, M. Firpo, R. De Vos, J. Fevery, F. Nevens, W.S. Hu, C.M. Verfaillie (2010) Human embryonic and rat adult stem cells with primitive endoderm-like phenotype can be fated to definitive endoderm, and finally hepatocyte-like cells. PLoS One 5: e12101.

Seguin, C.A., J.S. Draper, A. Nagy, J. Rossant (2008) Establishment of endoderm progenitors by SOX transcription factor expression in human embryonic stem cells. Cell Stem Cell 3: $182-195$.

Shamblott, M.J., J. Axelman, S. Wang, E.M. Bugg, J.W. Littlefield, P.J. Donovan, P.D. Blumenthal, G.R. Huggins, J.D. Gearhart (1998) Derivation of pluripotent stem cells from cultured human primordial germ cells. Proc Natl Acad Sci USA 95: 13726-13731.

-Shyh-Chang, N., G.Q. Daley (2013) Lin28: primal regulator of growth and metabolism in stem cells. Cell Stem Cell 12: 395-406.

Steigman, S.A., A. Ahmed, R.M. Shanti, R.S. Tuan, C. Valim, D.O. Fauza (2009) Sternal repair with bone grafts engineered from amniotic mesenchymal stem cells. J Pediatr Surg 44: 1120-1126, discussion 1126.

$>$ Sun, N., M.T. Longaker, J.C. Wu (2010) Human iPS cell-based therapy: considerations before clinical applications. Cell Cycle 9: 880-885.
Surani, M.A., K. Hayashi, P. Hajkova (2007) Genetic and epigenetic regulators of pluripotency. Cell 128: 747-762.

Takahashi, K., K. Tanabe, M. Ohnuki, M. Narita, T. Ichisaka, K. Tomoda, S. Yamanaka (2007) Induction of pluripotent stem cells from adult human fibroblasts by defined factors. Cell 131: 861-872.

Takakura, N., H. Yoshida, Y. Ogura, H. Kataoka, S. Nishikawa, S. Nishikawa (1997) PDGFR alpha expression during mouse embryogenesis: immunolocalization analyzed by wholemount immunohistostaining using the monoclonal anti-mouse PDGFR alpha antibody APA5. J Histochem Cytochem 45: 883-893.

Takayama, K., M. Inamura, K. Kawabata, K. Tashiro, K. Katayama, F. Sakurai, T. Hayakawa, M.K. Furue, H. Mizuguchi (2011) Efficient and directive generation of two distinct endoderm lineages from human ESCs and iPSCs by differentiation stage-specific SOX17 transduction. PLoS One 6: e21780.

Talbot, N.C., W.O. Sparks, A.M. Powell, S. Kahl, T.J. Caperna (2012) Quantitative and semiquantitative immunoassay of growth factors and cytokines in the conditioned medium of STO and CF-1 mouse feeder cells. In Vitro Cell Dev Biol Anim 48: 1-11.

Tanaka, S., T. Kunath, A.K. Hadjantonakis, A. Nagy, J. Rossant (1998) Promotion of trophoblast stem cell proliferation by FGF4. Science 282: 2072-2075.

Tesar, P.J., J.G. Chenoweth, F.A. Brook, T.J. Davies, E.P. Evans, D.L. Mack, R.L. Gardner, R.D. McKay (2007) New cell lines from mouse epiblast share defining features with human embryonic stem cells. Nature 448: 196-199.

Thomson, J.A., J. Itskovitz-Eldor, S.S. Shapiro, M.A. Waknitz, J.J. Swiergiel, V.S. Marshall, J.M. Jones (1998) Embryonic stem cell lines derived from human blastocysts. Science 282: 1145-1147.

Thomson, J.A., J. Kalishman, T.G. Golos, M. Durning, C.P. Harris, R.A. Becker, J.P. Hearn (1995) Isolation of a primate embryonic stem cell line. Proc Natl Acad Sci USA 92: 78447848 .

Thomson, J.A., J. Kalishman, T.G. Golos, M. Durning, C.P. Harris, J.P. Hearn (1996) Pluripotent cell lines derived from common marmoset (Callithrix jacchus) blastocysts. Biol Reprod 55: 254-259.

Turner, C.G., J.D. Klein, F.L. Gray, A. Ahmed, D Zurakowski, D.O. Fauza (2012) Craniofacial repair with fetal bone grafts engineered from amniotic mesenchymal stem cells. J Surg Res 178: 785-790.

Yasunaga, M., S. Tada, S. Torikai-Nishikawa, Y. Nakano, M. Okada, L.M. Jakt, S. Nishikawa, T. Chiba, T. Era (2005) Induction and monitoring of definitive and visceral endoderm differentiation of mouse ES cells. Nat Biotechnol 23: 1542-1550. 